\title{
Optimization of the cytogenetic protocol for Pangasianodon hypophthalmus (Sauvage, 1878) and Clarias gariepinus (Burchell, 1822)
}

\author{
Victor T. OKOMODA ${ }^{\text {Corresp., }}{ }^{1}$ ， Ivan C.C. KOH ${ }^{2}{ }^{\text {， Anuar HASSAN }}{ }^{2}$ ， Thumronk AMORNSAKUN ${ }^{3}$ ， Julia H. Z. MOH ${ }^{4}$ \\ , Sheriff Md SHAHREZA ${ }^{\text {corresp. } 2,4}$ \\ ${ }^{1}$ Department of Fisheries and Aquaculture, University of Agriculture Makurdi, Makurdi, Benue, Nigeria \\ 2 Aquaculture and Fisheries, Universiti Malaysia Terengganu, Kuala Nerus, Terengganu, Malaysia \\ 3 Technology and Industries, Prince of Songkla University, Mucang, Puttani, Songkla, Thailand \\ 4 Institute of Tropical Aquaculture (AKUATROP), Universiti Malaysia Terengganu, Kuala Nerus, Terengganu, Malaysia \\ Corresponding Authors: Victor T. OKOMODA, Sheriff Md SHAHREZA \\ Email address: okomodavictor@yahoo.com, shahreza@umt.edu.my
}

To obtain well spread chromosomes, the cytogenetic protocol for Pangasianodon hypophthalmus and Clarias gariepinus were optimized. This includes, the colchicine concentration $(0.01,0.025,0.05 \%)$ / exposure duration $(1,3$, and $5 \mathrm{~h})$, hypotonic solution (distilled water or $0.075 \mathrm{M} \mathrm{KCl}$ solution) /exposure duration ( $30 \mathrm{~min}, 1 \mathrm{~h}$, and $2 \mathrm{~h}$ ), the time of cell suspension preparation (at hypotonic treatment or before slide preparation) and chromosome aging period ( 0,3 , and 7 days in Carnoy's fixative). In addition, the type (i.e. fin, gill or kidney) and the amount of tissue $(10,50,100$ or $150 \mathrm{mg})$ were also investigated. Regardless of the species, the result obtained showed that well-spread chromosomes could be obtained using the following optimized protocol: Juveniles are injected with $0.05 \%$ colchicine (at $1 \mathrm{mlkg}^{-1}$ ) and allowed to swim for $3 \mathrm{~h}$. Then, $50 \mathrm{mg}$ of gill tissue is made into cell suspension in $0.075 \mathrm{M} \mathrm{KCl}$ for $1 \mathrm{~h}$. The cell suspension is treated in Carnoy's fixative (changed 3times at 20min interval) and then aged for three days. Finally, chromosome slides are made and stained with $10 \%$ Giemsa for $1 \mathrm{~h}$. 
1 Optimization of the cytogenetic protocol for Pangasianodon hypophthalmus (Sauvage, 1878)

2 and Clarias gariepinus (Burchell, 1822)

3 *1Victor T. OKOMODA, ${ }^{2}$ Ivan C.C. KOH, ${ }^{2}$ Anuar HASSAN, ${ }^{3}$ Thumronk 4 AMORNSAKUN, ${ }^{4}$ Julia H. Z. MOHAND AND **2, 4Sheriff Md, SHAHREZA

5 1Department of Fisheries and Aquaculture, College of Forestry and Fisheries, University of

6 Agriculture, Makurdi, Nigeria.

$7 \quad{ }^{2}$ School of Fisheries and Aquaculture Sciences, Universiti Malaysia Terengganu, Malaysia.

8 3epartment of Technology and Industries, Faculty of Science and Technology, Prince of

9 Songkla University, Thailand.

10 Institute of Tropical Aquaculture (AKUATROP), Universiti Malaysia Terengganu, Malaysia.

11 * Corresponding author e-mail: okomodavictor@yahoo.com; , phone no: +2348033319959

12 ** Corresponding author e-mail: shahreza@umt.my, phone no: +60192867794

\section{Abstract}

To obtain well spread chromosomes, the cytogenetic protocol for Pangasianodon hypophthalmus and Clarias gariepinus were optimized. This includes, the colchicine concentration $(0.01,0.025$, $0.05 \%$ ) / exposure duration $(1,3$, and $5 \mathrm{~h}$ ), hypotonic solution (distilled water or $0.075 \mathrm{M} \mathrm{KCl}$ solution) /exposure duration (30min, $1 \mathrm{~h}$, and $2 \mathrm{~h}$ ), the time of cell suspension preparation (at hypotonic treatment or before slide preparation) and chromosome aging period $(0,3$, and 7 days in Carnoy's fixative). In addition, the type (i.e. fin, gill or kidney) and the amount of tissue (10, 50,100 or $150 \mathrm{mg}$ ) were also investigated. Regardless of the species, the result obtained showed that well-spread chromosomes could be obtained using the following optimized protocol: Juveniles are injected with $0.05 \%$ colchicine (at $1 \mathrm{mlkg}^{-1}$ ) and allowed to swim for $3 \mathrm{~h}$. Then, $50 \mathrm{mg}$ of gill tissue is made into cell suspension in $0.075 \mathrm{M} \mathrm{KCl}$ for $1 \mathrm{~h}$. The cell suspension is treated in Carnoy's fixative (changed 3times at 20min interval) and then aged for three days. Finally, chromosome slides are made and stained with $10 \%$ Giemsa for $1 \mathrm{~h}$.

\section{INTRODUCTION}

The first level of genome analysis of any organism involves karyotyping of mitotic chromosomes to determine the genome organization at the cytological level (Gormam, 1973). It is an essential tool in providing basic information on breeding programs such as interspecific/intergeneric hybridization (Crego-Prieto et al., 2013), polyploidy induction (Christopher et al., 2010; Gilna et al., 2014; Thresher et al., 2014), and genetic improvement of commercial 
32 exploited or novel fish stocks targeted towards commercialization (Gui and (Zhu et al., 2012). An effective method of chromosome preparation is essential for cytogenetic research (Shao et al., 2010). Several techniques have been optimized to obtain well spread mitotic chromosomes in fish and this may differ for different species (e.g. as observed by Karami et al., 2010). These are usually in terms of chemical types, concentration, and duration of exposure. Firstly, the cells spindle fiber is arrested at metaphase by inoculation with a spindle poison (Rieder and Palazzo 1992; Silva et al., 2011). After which the cells are incubated in an appropriate hypotonic solution, to ensure the swelling and bursting of the nuclei (Moore and Best 2001). This is followed by fixation in Carnoy's fixative; preparation of a cell suspension; slide preparation and finally staining (Moore and Best 2001; Wang et al., 2010; Calado et al., 2013).

Despite the ease of chromosome preparation from eggs and larvae of fish (Shao et al., 2010, Karami et al., 2010; Amar-Basulto et al., 2011; Botwright 2015), cytogenetic studies involving specific tissues of fingerlings, juvenile or adult fish may have some merits over the use of whole larvae or egg. Aside the possibility of having a large amount of tissue from which metaphase chromosome can be isolated multiple times; this method has a pride of place in the characterization of the progenies of intergeneric hybridization (distance crosses) between different fish species from different genus (Okomoda et al., 2018). This is because of the need to match phenotypic characteristics of the progenies gotten with their equivalent cytogenetic characters due to the possible presence of ploidy polymorphism (see e.g. Liu et al., 2007; Zou et al., 2007; Zhao et al., 2015). However, similarities in the egg and larvae shape of the progenies at this stage of development make it practically very challenging to march phenotypic characters to different ploidy levels.

Chromosome preparation in post larvae fishes can be isolated from different tissues. These includes; fins (McPhail and Jones, 1966), gills (Yoo et al., 2017), scales (Ojima et al., 1972), kidney (Zhao et al., 2015; Huang et al., 2017) abdominal cavity fluid (Fan and Fox, 1990), gonads (Tan et al., 2004) to mention but a few. Despite successfully chromosomes isolation from these tissues, variations in the mitotic cell division rates could result in differences in the quality and quantity of the chromosome observed (Shelton et al. 1997). More so, the quantity or amount of tissue used for this processes could affect the concentration of cell suspension and consequently the visibility of chromosome spread. Similarly, the effectiveness of metaphase 
62 cellular interaction with cytogenetic chemicals could be affected by the time of "cellular 63 suspension" initiation (e.g. before or after chemical treatments). However, to the knowledge of 64 the researchers, there has been no report in which the tissue amount was optimized, nor the best 65 time for cellular suspension preparation elucidated. Hence, in addition to optimising colchicine 66 and hypotonic treatment, this study attempted to also optimise different tissue type/amount as

\section{Materials and Methods}

Juveniles of $P$. hypophthalmus and C. gariepinus (weighing between 10-50g) were obtained from the School of Fisheries and Aquaculture Science hatchery of the Universiti Malaysia Terengganu, in Malaysia. They were acclimatized for two weeks in rectangular fiberglass tanks and fed on a commercial diet (35\% Crude Protein) until the experiment was conducted. The method of Liu et al. (2007) was used as the basis of protocol optimization in a stepwise manner. For each optimized procedure, five fish were used (per species) for each treatment. Firstly, colchicine concentration and the duration of inoculation were investigated. Juveniles were intramuscularly injected with freshly prepared colchicine solution at $0.01,0.025$, and $0.05 \%$ colchicine for 1,3 and $5 \mathrm{~h}$ at $1 \mathrm{mlkg}^{-1}$ of the body weight of the juvenile. Using the selected concentration and duration of colchicine, the suitability of distilled water and $\mathrm{KCl}$ solution $(0.075 \mathrm{M})$ as a hypotonic solution was tested for $0.5,1$ and $2 \mathrm{~h}$. It is important to state that cytogenetic chemical treatment after colchicine treatment was done in a $1.5 \mathrm{ml}$ tube and a uniform volume of $600 \mu \mathrm{l}$ of these chemicals was adopted for comparative purposes. Following colchicine and hypotonic solution optimization, 10, 50, 100 and 150mg of fins, gill and kidney were extracted and followed by the procedure of Liu et al. (2007).

No alternative fixative, ratio or duration of exposure was considered in this study as freshly prepared Carnoy's solution (methanol-acetic acid at ratio 3:1) is commonly used with a unanimous exposure time of 20 mins with three changes (Fopp-Bayat and Woznicki 2006; Karami et al., 2010; Pradeep et al., 2011 etc.). However, the best time for making cell suspension was determined by initiating the process (i.e. chopping the tissue) during hypotonic treatment or 
92 prior to slide preparation (after fixation in Carnoy's solution). Before every subsequent step in 93 the formal treatment, the suspension is centrifuged at $2500 \mathrm{rcf}$ for $10 \mathrm{~min}$, and then the

94 95 96 supernatant is discarded leaving $1 \mathrm{ml}$ of the solution above the cell pellet. The cell is then resuspended using the next solution. Also, the effect of aging was investigated on the quality of chromosome spread. The cell suspension or tissue was allowed to age for 0,3 and 7 days in the Carnoy's solution followed by slide preparation. In all trial, slides were prepared by dropping method (two drops of the cell suspension on the slide at $1 \mathrm{~m}$ height) and incubation in $10 \%$ Giemsa stain (prepared in $0.01 \mathrm{M}$ phosphate buffer at $\mathrm{pH}$ 7) for $1 \mathrm{~h}$. Similarly, the metaphase spreads in all the trials were microphotographed using a Nikon Eclipse 80i compound microscope, and the images processed using the NIS element Basic Research software (at 100× magnification).

Chromosome identification and counting were done electronically using the Karyotyping Video Test Software (Version 3.1). In all the trial, the number of the well-spread chromosome observed was recorded except for the hypotonic treatment where the percentage of the complete / wellspread chromosome was computed. Prior to running analyses of data gotten in this study, normality, and homogeneity of data was tested (Tabachnick and Fidell 2001). For all treatment involving concentration/types vs duration of exposure (i.e. colchicine, and hypotonic solution respectively), a two-way Analysis of variance (ANOVA) was employed to evaluate the level of significant differences between each treatment (Using Fisher's LSD; $\mathrm{P} \leq 0.05$ ) and their interactions. A similar analysis was done for tissue type vs amount (quantity) and for the time of cell suspension preparation vs aging period. All data analysis in this study was done using Mini tab 14 computer software.

\section{Results}

The result obtained shows that the juveniles injected with $0.05 \%$ colchicine (at $1 \mathrm{mlkg}^{-1}$ ) for $3 \mathrm{~h}$ had better chromosome spread in both species when compared to other concentration and exposure times (Figure 1a and 2a). Treatment in KCL for $1 \mathrm{hr}$ (Figure 1b and 2b) and the use of $50 \mathrm{mg}$ of gill tissue sample (Figure 1c and 2c) also proved to be more effective in this study. In addition, preparation of cell suspension before hypotonic treatment and aging for 3 days resulted in well spread chromosomes (Figure 1d and 2d). A sample of the metaphase chromosome produced in Clarias gariepinus and Pangasianodon hypophthalmus are presented in Figure 3. 
123 The choice of a right concentration and duration of exposure of colchicine is very important.

124 This is because insufficient amount could fail to arrest the target cells at metaphase stage (Rieder 125 and Palazzo 1992; Caperta et al., 2006), however too high a concentrations or prolonged 126 exposure, on the other hand, may lead to chromosomal condensation (Wood et al., 2001). The 127 optimum values recorded in this study for colchicine (i.e. $0.05 \%$ for $3 \mathrm{~h}$ ) is similar to the findings 128 for optimization in post-larval stages of some other fish species (e.g. Liu et al., 2001; Botwright 129 2015; Zhao et al., 2015; Huang et al., 2017). This is, however, at variance with the finding of 130 Shao et al., (2010) for eggs and larvae of Japanese flounder (Paralichthys olivaceus) and summer 131 flounder (Paralichthys dentatus) as they reported best metaphase chromosomes with $0.02 \%$ for 132 1-2hours. While this may be a high enough concentration to penetrate the vitelline membrane of 133 the egg and the tin walls of the larvae, the present study shows that this is not optimum for the 134 post-larvae of African and Asian catfishes. This is despite using intramuscular injection 135 procedure which was thought to be an efficient method to deliver the spindle poison to the fish 136 tissues considering the numerous blood vessels in the skin (Tan et al., 2004; Zhao et al., 2015; 137 Huang et al., 2017).

138 Subsequent upon mitotic spindle inhibition, it is pivotal to use an appropriate hypotonic solution 139 to swell the nuclei of the mitotic cell to the point of bursting and spread out the chromosomes 140 (Moore and Best 2001). Choosing an improper hypotonic solution and incubation period may 141 result in overlapping or significant loss of chromosomes (Baksi and Means 1988). The efficacy 142 of Potassium chloride $(\mathrm{KCl} 0.075 \mathrm{M})$ over distil water was demonstrated in this study. In both 143 species, the number of clear metaphase chromosome spreads was significantly higher using the 144 former than the latter. Karami et al., (2010) had earlier stated that using $\mathrm{KCl}$ caused extensive 145 cell burst and chromosomal loss when compared to distilled water treated larvae of $C$. 146 gariepinus. However, chromosome loses in this study was observed in both hypotonic solutions 147 when the tissue was incubated beyond 1hour while below this reference point, metaphase 148 chromosomes were largely overlapping. The differences in observation of the two studies despite 149 the similarity of the species may be linked to the different developmental stages of fish used.

150 The present study has for the very first time, shown that too much or too little of tissue amount 151 could affect the number of identifiable metaphase chromosomes. The optimum amount as 
152 observed in this study was 50mg. While the scanty number of chromosome observed below $15350 \mathrm{mg}$ could be explained by reduced cell concentration, the observation beyond the reference 154 amount may be because of high cell/tissue concentration which resulted into darkening of the 155 slide background. Hence, this may have covered some well spread metaphase chromosome and 156 the spaces between chromatids, consequently making them unobservable. However, this may be 157 remedied (hypothetically) by respectively concentrating or diluting the final volume of cell 158 suspension prepared in the Carnoy's solution. The difference in the results from the different 159 tissue is largely connected with the mitotic cell division rates of these tissues as earlier stated. 160 This assumption is similar to the findings of Shelton et al. (1997).

161 The observation of a higher number of well-spread metaphase chromosomes in the gills may be 162 connected to the vulnerability of the gills to environmental imbalances (Moyle and Cech, 1996).

163 This may imply that cell division in this organ could be more rapid to compensate damage from 164 environmental influences. Wakahara (1972) had earlier demonstrated that the mitotic cell 165 division rate of the ventral tail-fin epidermis of the larval African clawed frog (Xenopus laevis) is 166 largely affected by changes in environmental factors. Therefore, future studies can be designed 167 to understand the effect of environmental changes on the proliferation of the mitotic cell in 168 different tissues of fish. However, the differences in mitotic division rates may also explain the 169 differences in the response to colchicine and hypotonic solutions treatment by the two fishes 170 understudied in this research.

171 The observation from this study suggests that making cell suspension during hypotonic treatment 172 led to an increased number of observable metaphase chromosome than initiating this process 173 prior to slide preparation. The efficiency of the former is likely connected to the increased 174 surface area of the dissociated cell to the different chemical treatments, hence making their effect 175 more pronounced than the latter whose tissue was intact through the chemical treatment phase 176 until slide preparation. Similarly, aging of the cell suspension or tissue for three days in the 177 Carnoy's fixative produces better chromosome spread than preparing slide on the very day of 178 cytogenetic treatment or seven days after. While the underlining principles responsible for this 179 observation are not well understood, it was speculated that aging might have dissociation effect 180 on the chromosomes. This is because appreciable percentages of the identifiable chromosome in 181 the slide prepared on the very day of cytogenetic treatment were compacted and overlapping, 
182 while significant chromosome loss was characteristics of the observations after seven days of

183 aging. However, these observations are lesser when cells were aged for just three days.

184

185

186

187

188

189

190

191

192

193

194

195

196

197

198

199

200

201

202

203

204

205

206

207

208

209

210

211

\section{Conclusions}

The metaphase chromosome produced in this study could be used for karyotype analysis. Although species-specific technicalities have been recommended to obtain well-spread metaphase chromosomes in different species (Karami et al., 2010), the method described in this study, however, seem to give a satisfactory result for both species using a similar protocol. However, the method of slide preparation by dropping (at 1meter height) reported in this study could cause loss of chromosome due to technical difficulties. Hence, short distance dropping on the slide with the vapor layer could be an alternative method of choice for researchers adopting this optimized procedure. This protocol may also be effective for cytogenetic studies involving other closely related catfish species such as Clarias macrocephalus, Heterobranchus longifilis, Pangasius gigas etc. This could be the focus of future researches.

\section{Acknowledgments}

The authors are indebted to the School of Fisheries and Aquaculture Science, Universiti Malaysia Terengganu, Malaysia for providing juveniles of P. hypophthalmus and C. gariepinus used in this study. We also acknowledge the help of some technical staffs of the PPSPA hatchery department and laboratory officers of AKUATROP during experimental trials of this study. This study is part of the first author's Ph. D research.

\section{References}

Amar-Basulto G., F. Lafarga-De la Cruz, P. Iturra-Constant, and C. Gallardo-Escarate. 2011. Karyotype analysis of interspecific hybrids between Haliotis rufescens and Haliotis discus HANNAI. Aquaculture Research, 42: 1460-1466

Baksi S., and J. Means. 1988. Preparation of chromosomes from early stages of fish for cytogenetic analysis. Journal of Fish Biology 32: 321-325

Botwright N. A. 2015. Karyotype comparison between Haliotis rubra, H. laevigata and the interspecific hybrid. Aquaculture Research 46: 236-241

Calado L. L., L. A. C. Bertollo, G. W. W. Fd Costa, and W. F. Molina. 2013. Cytogenetic studies of Atlantic mojarras (Perciformes-Gerreidae): chromosomal mapping of $5 \mathrm{~S}$ and $18 \mathrm{~S}$ ribosomal genes using double FISH. Aquaculture Research 44: 829-835 
212 Caperta A., M. Delgado, F. Ressurreic,ão, A. Meister, R. Jones, W. Viegas, and A. Houben.

213

214

215

216

217

218

219

220

221

222

223

224

225

226

227

228

229

230

231

232

233

234

235

236

237

238

239

240

241

242

243

244

245

246

247

248

249 2006. Colchicine-induced polyploidization depends on tubulin polymerization in cmetaphase cells. Protoplasma 227:147-153

Christopher J. S. G., A. G. Murugesan, and N. Sukumaran 2010. Induction of meiotic gynogenesis in the stinging catfish Heteropneustes fossilis (Bloch) and evidence for female homogamety. Aquaculture Research 42: 129-138

Crego-Prieto V., D. Danancher, D.Campo, J. Perez, E. Garcia-Vazquez, and A. Roca. 2013. Interspecific introgression and changes in population structure in a flatfish species complex after the Prestige accident. Mar Poll Bull 74: 42-49

Fan, Z., and D. P. Fox. 1990. A new method for fish chromosome preparation. Journal of Fish Biology. 37, 553-561.

Fopp-Bayat D., and P. Woznicki. 2006. Verification of ploidy level in sturgeon larvae. Aquaculture Research 37:1671-1675

Gilna B., J. Kuzma, and S. S. Otts. 2014. Governance of genetic biocontrol technologies for invasive fish. Biol Invasion 16: 1299-1312

Gorman G. C. 1973. The Chromosomes of the Reptilia, a Cytotaxonomic Interpretation. In: Cytotaxonomy of Vertebrate Evolution (Chiarelli AB and Capanna E, eds.). Academic Press, London, 349-424.

Huang W., Q. Liu, J. Xie, W. Wang, J. Xiao, S. Li, H. Zhang, Y. Zhang, S. Liu and H. Lin. 2017. Characterization of triploid hybrid groupers from interspecies hybridization (Epinephelus coioides + × Epinephelus lanceolatus 0 ). Aquaculture Research, 47(7), 2195-2204

Karami A., P. S. Araghi, M. A. Syed, and S. P. Wilson. 2010. Chromosome preparation in fish: effects of fish species and larval age. International Aquatic Research 7: 201-210

Liu L.S., Q. Qin, J. Xiao, W. Lu, J. Shen, W. Li, J. Liu, W. Duan, C. Zhang, M. Tao, R. Zhao, J. Yan, and Y. Liu. 2007. The Formation of the Polyploid Hybrids From Different Subfamily Fish Crossings and Its Evolutionary Significance. Genetics 176: 1023-1034

Liu, S., Y. Liu, G. Zhou, X. Zhang, C. Luo, H. Feng, X. He, G. Zhu, and H. Yang. 2001. The formation of tetraploid stocks of red crucian carp $\times$ common carp hybrids as an effect of interspecific hybridization. Aquaculture 192, 171-186.

McPhail, J.D., and R. L. Jones., 1966. A simple technique for obtaining chromosomes from teleost fishes. J. Fish. Res. Board Can. 23, 767-768.

Moore C. M., and R. G. Best. 2001. Chromosome preparation and banding. eLS. doi:10.1038/npg.els.0001444

Moyle, P. B. and J. J. Jr. Cech. 1996. Fishes: An Introduction to Ichthyology. 3rd ed. Upper Saddle River, Prentice Hall. Upper Saddle River, NJ. 590pp

Ojima, Y., S. Takayama, and K. Yamamoto. 1972. Chromosome preparation from cultured scale epithelium of teleost fish. Jpn. J. Genet. 47, 445-446. 
250

251

252

253

254

255

256

257

258

259

260

261

262

263

264

265

266

267

268

269

270

271

272

273

274

275

276

277

278

279

280

281

282

283

284

285

286

287
Okomoda V.T., Koh I.C.C., Hassan A., Amornsakun T. and Shahreza M.S. (2018). Performance and characteristics of the progenies from the crosses of Pangasianodon hypophthalmus (Sauvage, 1878) and Clarias gariepinus (Burchell, 1822). Aquaculture. 489: 96-104.

Pradeep P. J., T. C. Srijaya, R. B. M. Zain, A. Papini, and A. K. Chatterji. 2011. A simple technique for chromosome preparation from embryonic tissues of teleosts for ploidy verification. Caryologia 64: 233-239

Rieder C. L., and R. E. Palazzo. 1992. Colcemid and the mitotic cycle. J Cell Sci 102:387-392

Shao C. W., P. F. Wu, X. L. Wang, Y. S. Tian, and S. L. Chen. 2010. Comparison of chromosome preparation methods for the different developmental stages of the halfsmooth tongue sole, Cynoglossus semilaevis. Micron 41.pp 47-50

Shelton W. L., S. D.Mims, J. A. Clark, A. E. Hiott, and C. Wang, 1997. A temperaturedependent index of mitotic interval (s0) for chromosome manipulation in paddlefish and shovelnose sturgeon. Prog Fish Cult 59: 229-234

Silva T. L., M. I. A. Silva, L. P. R. Venancio, C. E. S. Zago, V. A. G. Moscheta, A. V. B. Lima, L. D. Vizotto, J. R. Santos, C. R. Bonini-Domingos and M. T. V. Azeredo-Oliveira. 2011. Simple method for culture of peripheral blood lymphocytes of Testudinidae. Genetic and Molecular Research. 10: 3020-3025

Tabachnick B. G., and L. S. Fidell. 2001. Using multivariate statistics Boston: Allyn and Bacon. Bamberger et, 31, 1 .

Tan X., J. G. Qin, B. Chen, L. Chen, and Li. X. 2004. Karyological analyses on redclaw crayfish Cherax quadricarinatus (Decapoda: Parastacidae). Aquaculture 234: 65-76.

Thresher R. E., K. Hayes, N. J. Bax, J. Teem, T. J. Benfey, F. Gould 2014. Genetic control of invasive fish: technological options and its role in integrated pest management. Biol Invasion 16:1201-1216

Wakahara M. 1972. Daily variation in mitotic rate in tail-fin epidermis of larval Xenopus laevis and its modification by pineal organ-subcommissural organ system and photoperiods. Neuroendocrinol 9:267-277

Wang S., Y. Su, S. Ding, Y. Cai, and J. Wang. 2010. Cytogenetic analysis of orange-spotted grouper, Epinephelus coioides, using chromosome banding and fluorescence in situ hybridization. Hydrobiol 638:1-10

Wood K. W., W. D. Cornwell, J. R. Jackson. 2001. Past and future of the mitotic spindle as an oncology target. Curr Opin Pharmacol 1:370-377

Yoo G. Y., T. H. Lee, H. W. Gil, S. G. Lim and I. S. Park. 2017. Cytogenetic analysis of hybrids and hybrid triploids between the river puffer, Takifugu obscurus, and the tiger puffer, Takifugu rubripes. Aquaculture Research. 2017;1-14.

Zhao H., H. Zou, and W. Lu. 2015. Ploidy polymorphism and morphological variation among reciprocal hybrids of Pseudosciaena crocea () 3 Miichthys miiuy (ð). Aquaculture Research, 2015, 1-9 
288 Zhu D. M., W. Song, K. Yang, X. J. Cao, Y. Gul and W.M. Wang. 2012. Flow cytometric determination of genome size for eight commercially important fish species in China. In Vitro Cellular and Developmental Biology. Anim 1al 48, 507-517.

291 Zou J., L.G. Liu, X. L. Chen, N. Qing, and C.W. Dong 2007. Karyotypic analysis of the multiple 292 tetraploid allogynogenetic pengze crucian carp and its parents. Aquaculture 237. 117293 129. 


\section{Figure 1 (on next page)}

Effects of different treatments on the number of clear and identifiable metaphase chromosome spreads in Clarias gariepinus.

(A) Colchicine concentration $x$ duration of exposure interaction. (B) Tissues type $x$ mass of tissue interaction. (C) Hypotonic treatment $x$ duration of exposure. (D) Cell suspension preparation $\times$ aging time. Data shown are Mean \pm SE. Bars with different letters are significantly different from each other $(P \leq 0.05)$. 

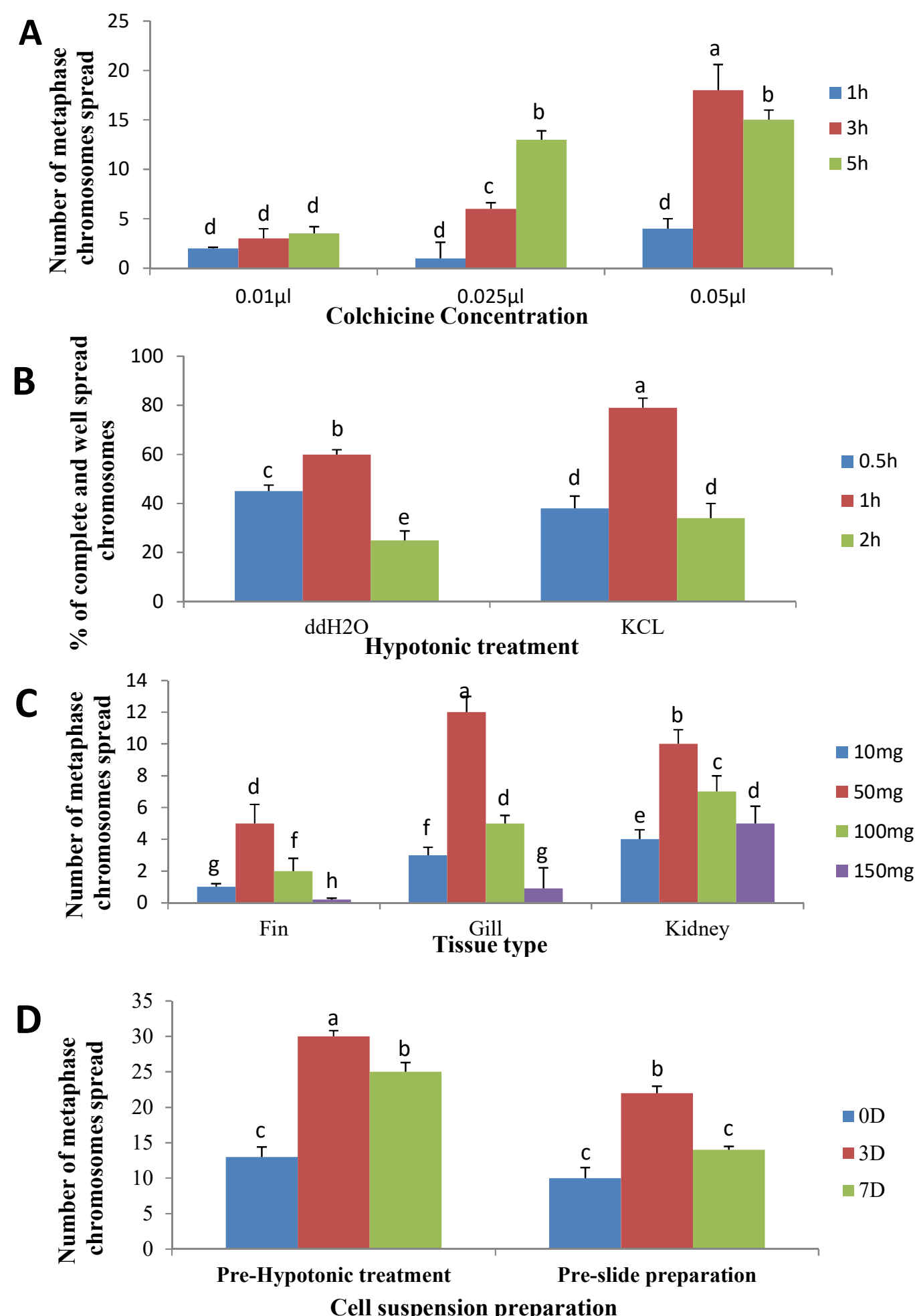

Figure 1: Effects of different treatments on the number of clear and identifiable metaphase chromosome spreads in Clarias gariepinus. (A) Colchicine concentration $\times$ duration of exposure interaction. (B) Tissues type $\times$ mass of tissue interaction. (C) Hypotonic treatment $\times$ duration of exposure. (D) Cell suspension preparation $\times$ aging time. Data shown are Mean \pm SE. Bars with different letters are significantly different from each other $(\mathrm{P} \leq 0.05)$. 
Figure 2 (on next page)

Effects of different treatments on the number of clear and identifiable metaphase chromosome spreads in Pangasianodon hypophthalmus.

(A) Colchicine concentration $x$ duration of exposure interaction. (B) Tissues type $x$ mass of tissue interaction. (C) Hypotonic treatment $x$ duration of exposure. (D) Cell suspension preparation $\times$ aging time. Data shown are Mean \pm SE. Bars with different letters are significantly different from each other $(P \leq 0.05)$. 

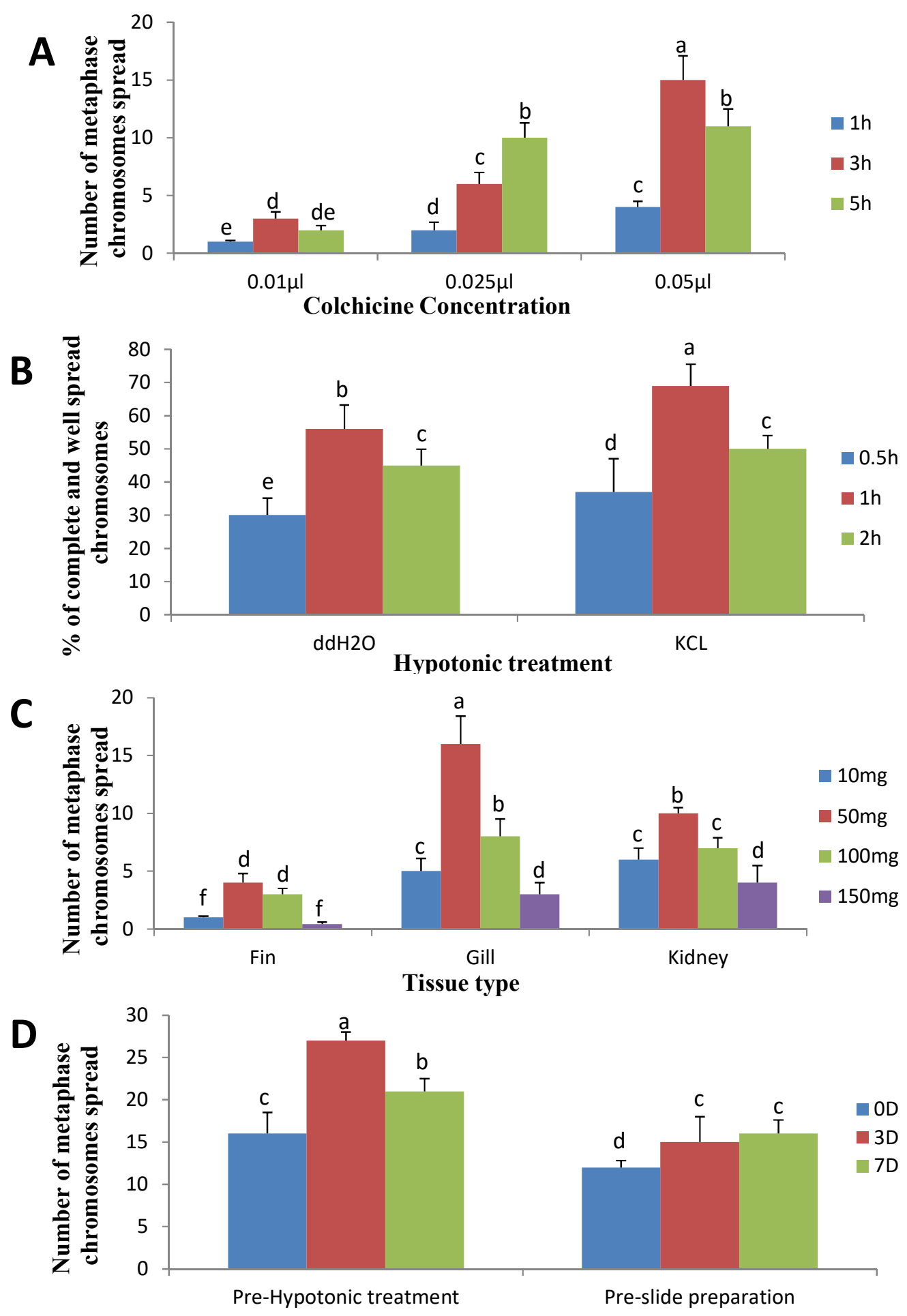

Cell suspension preparation

Figure 2: Effects of different treatments on the number of clear and identifiable metaphase chromosome spreads in Pangasianodon hypophthalmus. (A) Colchicine concentration $\times$ duration of exposure interaction. (B) Tissues type $\times$ mass of tissue interaction. (C) Hypotonic treatment $\times$ duration of exposure. (D) Cell suspension preparation $\times$ aging time. Data shown are Mean \pm SE. Bars with different letters are significantly different from each other $(\mathrm{P} \leq 0.05)$. 


\section{Figure 3 (on next page)}

Metaphase chromosome of (a) Clarias gariepinus $(2 n=56)$ and (b) Pangasianodon hypophthalmus $(2 \mathrm{n}=60)$.

Bar $=5 \mu \mathrm{m}$. 


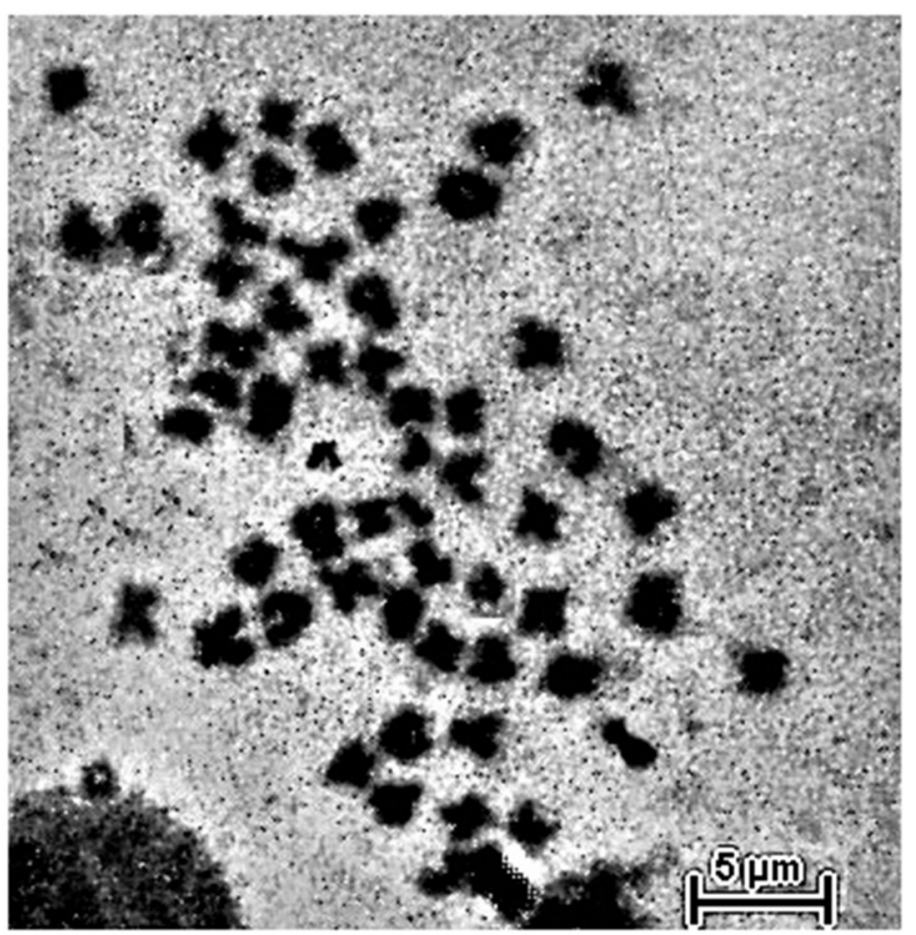

A

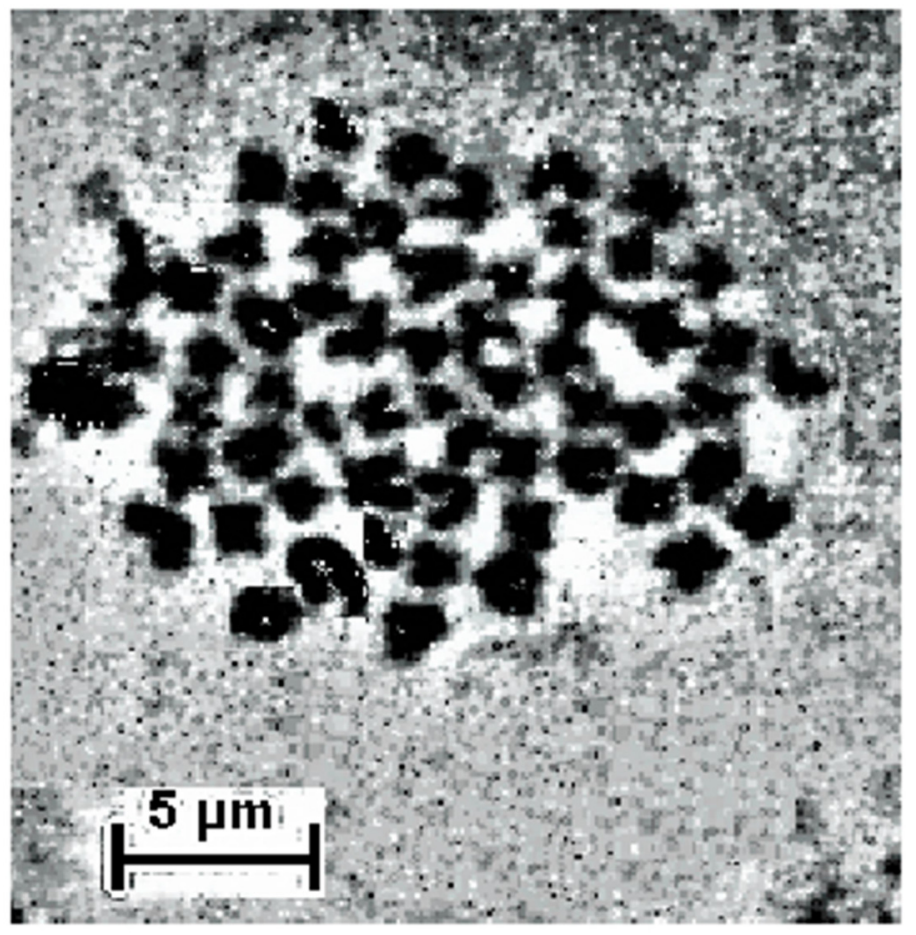

B 